\title{
In silico Screening of Phytochemicals of Ocimum sanctum against Main Protease of SARS-CoV-2
}

Pranab Kishor Mohapatra ${ }^{1, *}$, Kumar Sambhav Chopdar ${ }^{2}$, Ganesh Chandra Dash $^{3}$, Mukesh Kumar Raval ${ }^{1, \#, *}$

1. Department of Chemistry, C. V. Raman Global University, Bidyanagar, Mahura, Janla, Bhubaneswar, Odisha 752054, India

2. Department of Chemistry, APS College, Roth, Balangir, Odisha 767061, India

3. Department of Zoology, Rajendra College, Balangir, Odisha 767002, India

* Authors for Correspondence

E-Mail:mohapatrasu@gmail.com;mraval@yahoo.com

\# Present Address: Stone Building, Opp: Mission School, Balangir 767001, Odisha, India 


\begin{abstract}
COVID19 has compelled the scientific community to search for an effective drug that can cure; a vaccine or an immunity booster that can prevent the disease. As of now, it is tough to discover a new drug and vaccine discovery is even tougher. Drug repurposing is a shortcut to drug discovery for COVID19. Even this has been proved unsatisfactory. Symptomatic treatment and immunity boosters are only alternatives left. Holy Tulsi (Ocimum sanctum) has been known as an ancient remedy for cure of common cold and respiratory ailment in India vis-a-vis also has been prescribed as one of the recommended ingredients in the immunity booster preparations. The ethanolic extract of aerial parts of Tulsi is reported to contain flavonoids and polyphenolic acids, which are also reported earlier to have anti-viral properties experimentally. Therefore, we undertake the in silico analysis of the phytochemicals as inhibitors of main protease of SARS-CoV-2 virus. The result suggests that the flavonoids and polyphenolic compounds of Tulsi, especially luteolin-7-O-glucuronide and chlorogenic acid may covalently bind to the active residue Cys145 of main protease and irreversibly inhibit the viral enzyme. Further experimental validations are required to establish the theoretical findings.
\end{abstract}

Keywords: Ocimum sanctum; SARS-CoV-2; Phytochemicals; Covalent Docking; Molecular Dynamics

\title{
INTRODUCTION
}

Severe acute respiratory syndrome virus 2 (SARS-CoV-2) causes coronavirus disease 2019 (COVID-19). The virus is highly contagious resulting in pandemic condition in the world. Human lives are at risk and socioeconomic condition is dragged to the bottom line. The human race is fighting with the situation from all fronts, including social, economic and medical science. Medically the rapid predation of the virus has to be checked by prevention (vaccination, immunity boosting), mitigation of symptoms (symptomatic treatment), and cure (antiviral drug administration).

In the absence of vaccine and specific drug only option is symptomatic treatment and immunity boosting nutraceutics. Ministry of AYUSH, Government of India has recommended and permitted for clinical trial of Ayurvedic preparations which are claimed to be immunity boosters. Such preparations have Tulsi, Sunthi (dried ginger), Cinnamon, and Giloy as ingredients. Tulsi (Ocimum sanctum) is prevalent age old house hold remedy to common cold and fever in India. Tulsi may be effective against respiratory tract infection in general. Several studies over a period reveal the anti-inflammatory, antibacterial, antiviral, antipyretic effects of phytochemicals of Tulsi (Mondal et al., 2009; Bhasin 2012; Zaharan et al., 2020). In the present study the phytochemicals in ethanolic extract of leaves of Tulsi (also known as holy basil) have been screened in silico against the main protease $\left(\mathrm{M}^{\text {pro }}\right)$ to investigate the potent inhibitors.

\section{METHODS}

\section{Phytochemicals}

The phytochemicals in alcoholic extract of leaves and aerial parts of Tulsi reported by Mondal et al. (2009) were considered for the present study (Fig. 1). Majority of the 
phytochemicals belong to the flavonoids and polyphenolic compounds. The structural coordinate files were downloaded from PubChem (http://www.pubchem.ncbi.nlm.nih.gov).<smiles>O=C(O)c1ccccc1</smiles>

2,3-dihydroxybenzoic acid CID_19

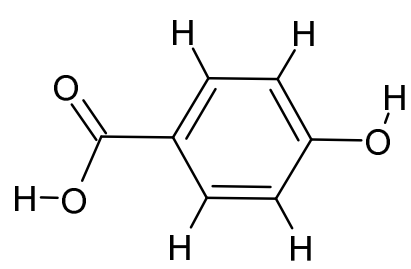

4-hydroxybenzoic acid CID_135

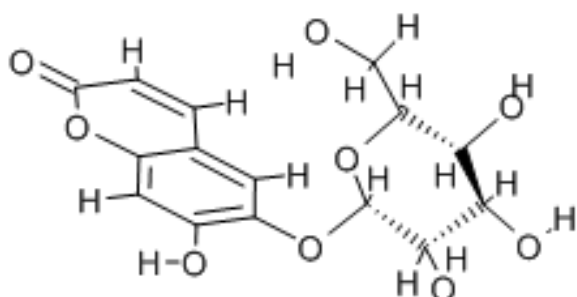

Aesculin CID 5281417

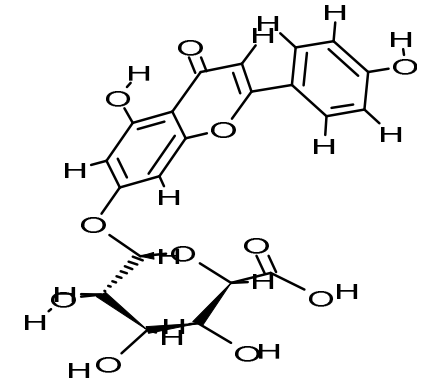

Apigenin_7-glucuronide CID_5319484<smiles>OOc1ccc(/C=C/COC2C(O)C(O)C3C=CC3C2O)cc1O</smiles>

Chlorogenic Acid

CID_1794427<smiles></smiles>

Esculetin

CID_5281416<smiles>O=c1cc(-c2ccc(O)c(O)c2)oc2cc(O)cc(O)c12</smiles>

Apigenin<smiles>O=C(O)/C=C/c1ccc(O)c(O)c1</smiles>

Caffeic acid CID_689043

CID_5280443

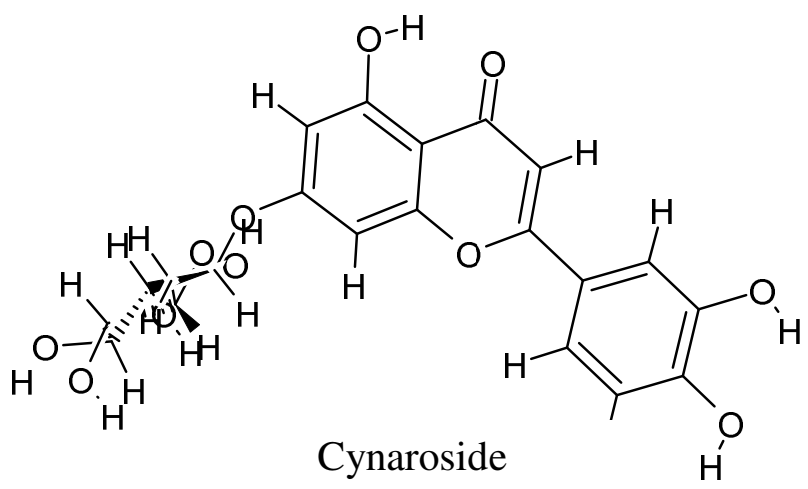

CID_5280637<smiles>CCOC(=O)c1ccc(O)c(O)c1O</smiles>

Ethyl Gallate CID_13250<smiles>O=C(O)c1ccc(O)c(O)c1O</smiles>

Gallic Acid CID_370<smiles>[2H]c1c(-c2ccc(O)c(O)c2O)oc2cc(O)c(C3O[C@H](C(O)O)[C@@H](O)[C@H](O)[C@H]3O)c(O)c2c1=O</smiles><smiles></smiles> 


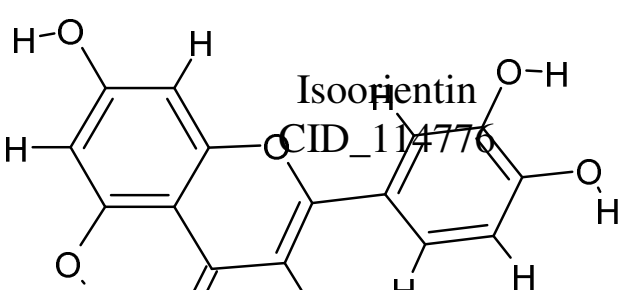

Luteolin

CID_5280445

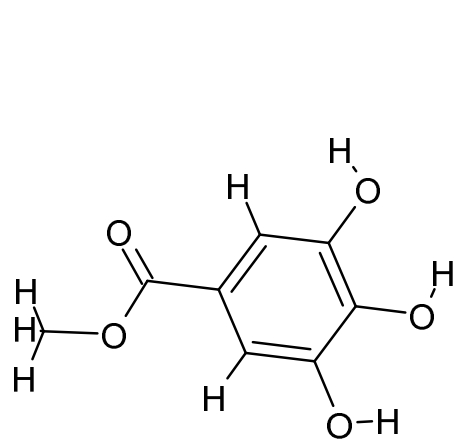

Methyl Gallate

CID_7428

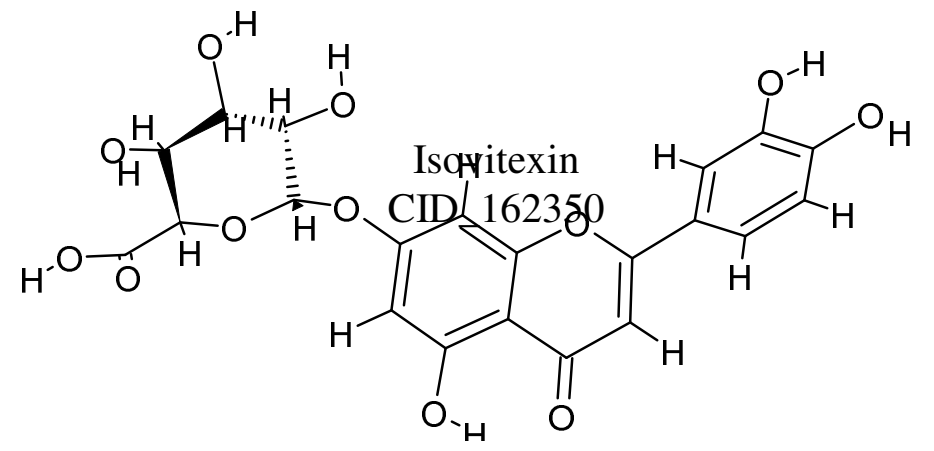

' uteolin-7-O-glucuronide

CID_13607752

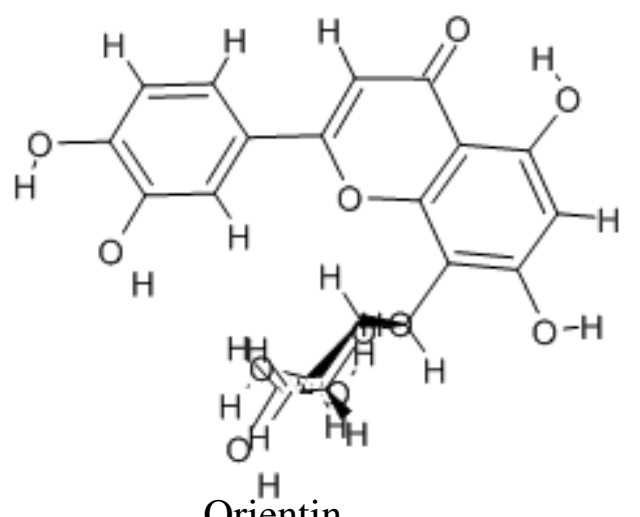

Orientin

CID_5281675

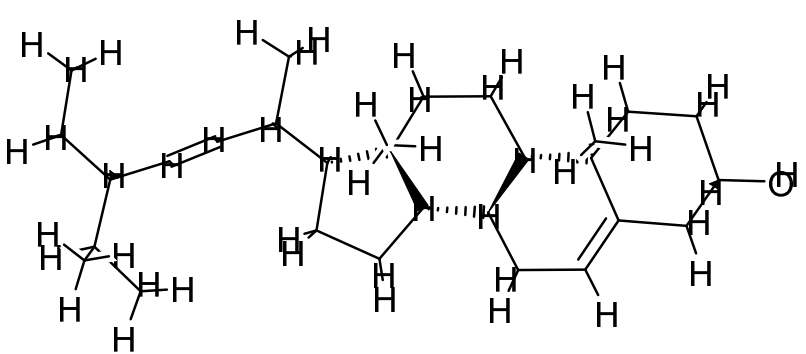

Stigmasterol

CID_5280794

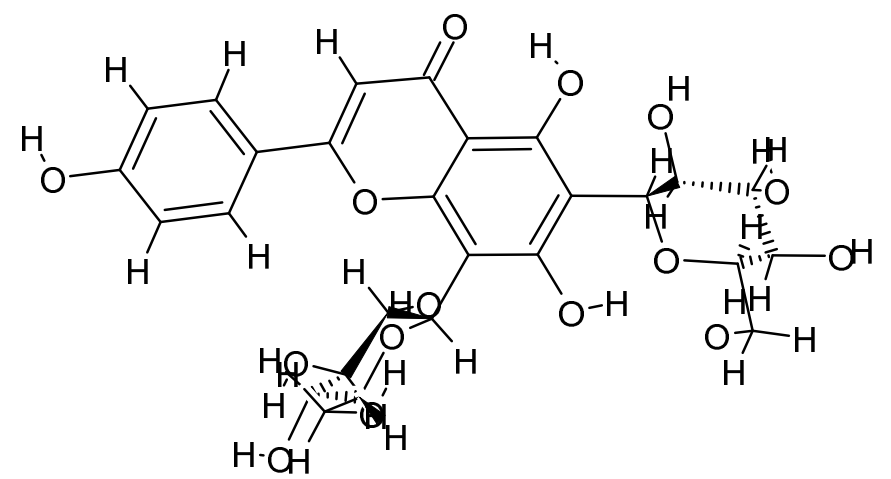

Vicenin

CID_442664
Molludistin

CID_44258315

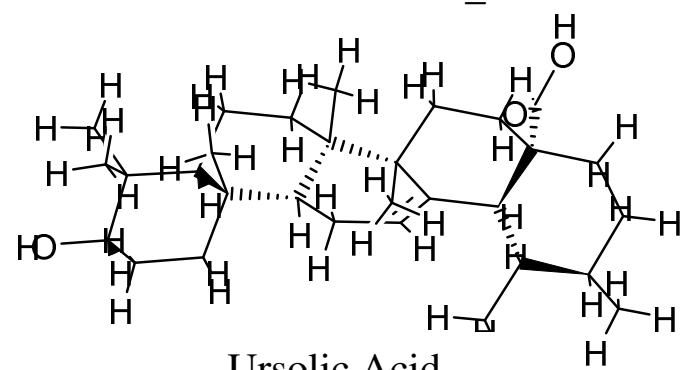

Ursolic Acid

CID_64945

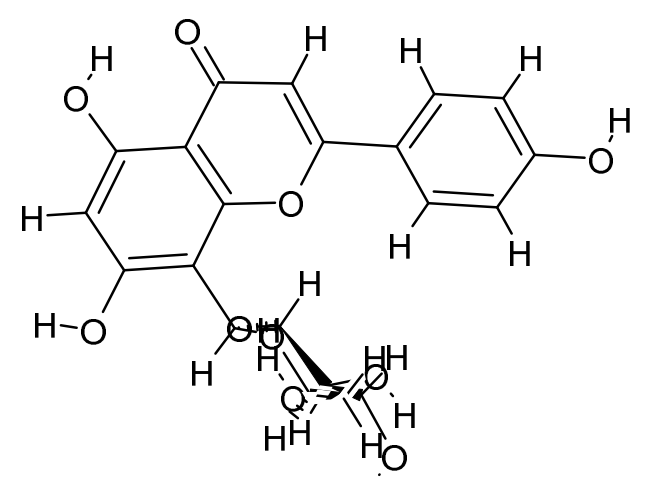

$\mathrm{H}$

Vitexin

CID_5280441

Figure 1. The structural representation phytochemicals in alcoholic extract of leaves and aerial parts of Tulsi. Common names with PubChem ID are mentioned below each structure (http://www.pubchem.ncbi.nlm.nih.gov). 


\section{Main Protease}

The 3D crystallographic structural coordinate file of the main protease of SARS-CoV-2, $\mathrm{M}^{\text {pro }}$ (PDB ID 6y2f; Zhang et al., 2020), was downloaded from the protein data bank (https://www.rcsb.org/pdb). The ligand binding site in the protease and interaction of ligands with residues in the cavity are depicted in Fig. 2.

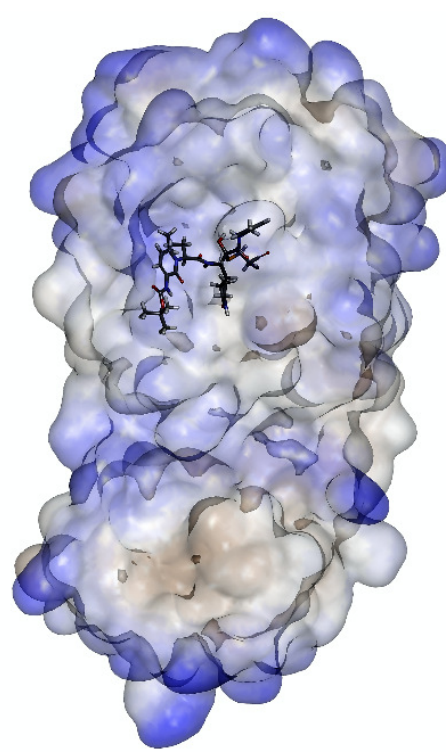

A

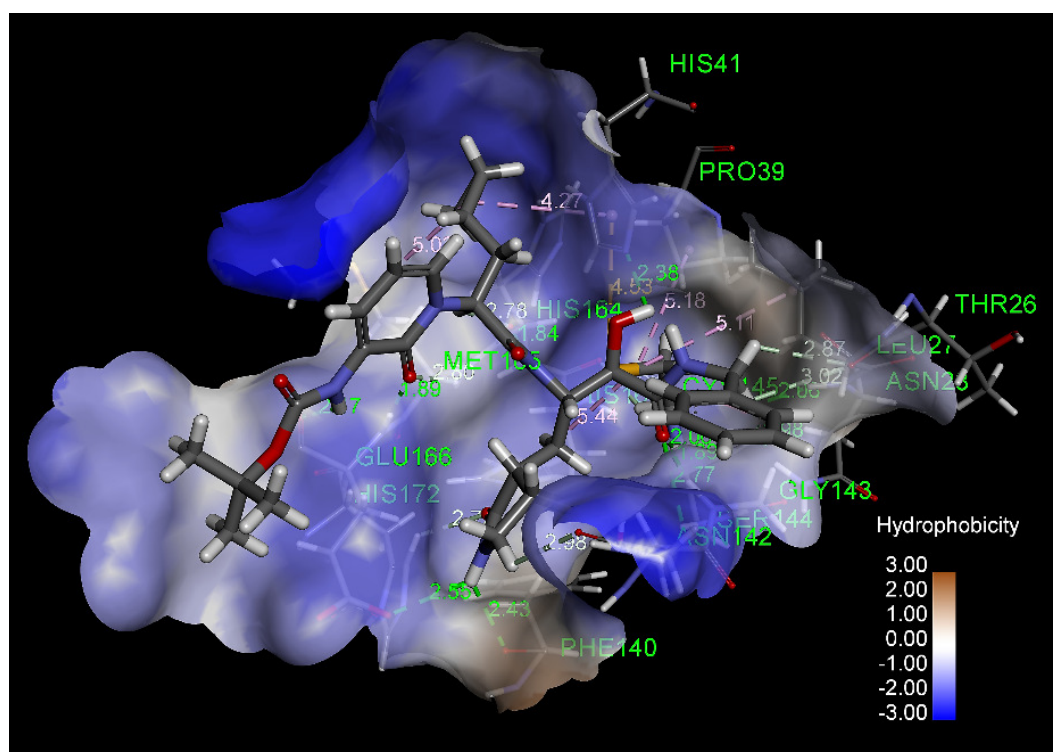

B

Figure 2. The inhibitor O6K bound to the active site of main protease of SARS-CoV-2 virus is depicted. A, O6K (stick representation) bound the protein surface (hydrophobic); B, close up of the active site with residues involved in the interaction with the ligand (PDB ID 6y2f; Zhang et al., 2020)

\section{Docking}

The Target and the Active Site

Structure of SARS-CoV-2main protease (PDB ID 6y2f A) was taken as the target (Fig. 2). The binding of the inhibitor O6K ( $\{$ tert $\}$-butyl $\{\mathrm{N}\}-[1-[(2 \sim\{\mathrm{S}\})-3$-cyclopropyl-1oxidanylidene-1-[[(2 \{S\},3 \{R\})-3-oxidanyl-4-oxidanylidene-1-[(3 $\{\mathrm{S}\})$-2-oxidanylidenepyrrolidin-3-yl]-4-[(phenylmethyl)amino]butan-2-yl]amino]propan-2-yl]-2-oxidanylidene-py ridin-3-yl] carbamate) in the structure was used to identify the active site residue applying ArgusLab 4.0.1. The software is available at $h t t p: / / w w w . a r g u s l a b . c o m . ~ O 6 \mathrm{~K}$ was selected and made a ligand group. This ligand group was selected to make binding site from the group. 
The binding site provided a list of residues present in the active site of 6y $2 \mathrm{f}$ A. They are Thr26, His41, Phe140, Gly143, Cys145, His164, Met165, Glu166, and His172.

\section{Screening}

Docking scores for the phytochemicals of Tulsi were obtained on in silico screening by AutoDock Vina (Trott and Olson, 2010) using YASARA (Krieger and Vriend, 2014). The ligands and the active site residues Thr26, His41, Phe140, Gly143, Cys145, His164, Met165, Glu166, and His172were allowed to be flexible during docking.

\section{Covalent Docking}

AutoDock 4.2 with general Lamarckian algorithm with AMBER 3 force field in YASARA was used for covalent docking of the phytochemicals (Krieger and Vriend, 2014).YASARA Structure module provides a tuned derivative of the AutoDock, originally developed by Scripps Research Institute (Morris et al. 1998).

Flexible side chain method was applied for the covalent docking using AutoDock 4.2 (Bianco et al., 2016). The ligand coordinate file was modified at the siteof alkylation byjoining the two target residue atoms, with ideal chemical geometry. Thesetwo ligand atoms were then mapped on thematching atoms in the receptor structure to createthe covalent bond with the residue before runningthe docking. The docking process was run with thecomplex being treated as a fully flexible side chain.

In the present study the warheads used are polyphenolic ring (free radical mechanism, Mazzei et al., 2017) and $\alpha, \beta$ - unsaturated carbonyl (Michael addition mechanism, Jackson et al., 2017) moieties for Cys145 covalent bonding (Fig. 3).

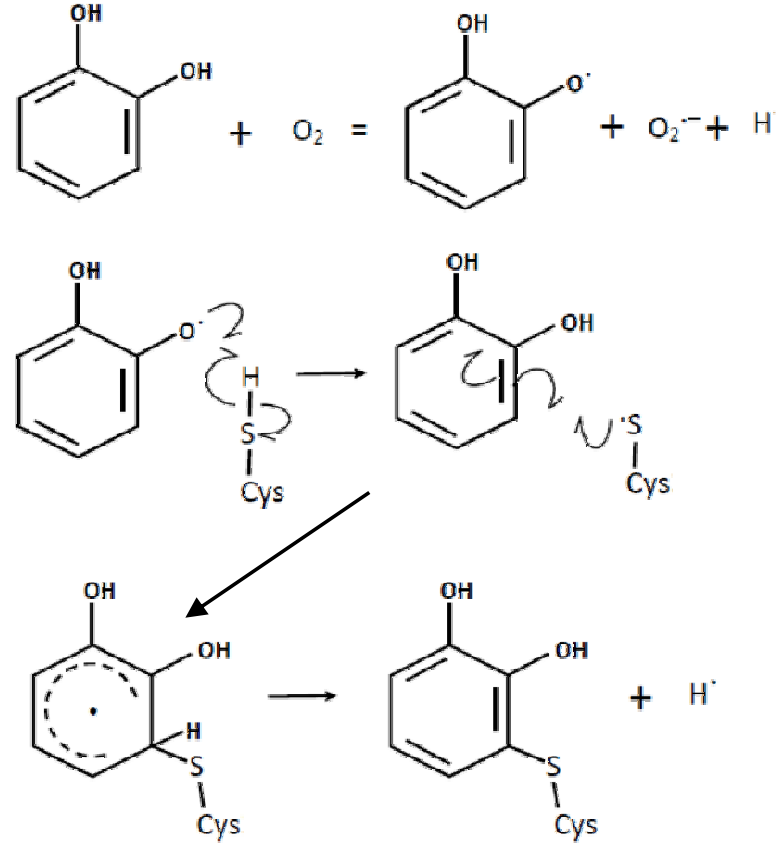

A

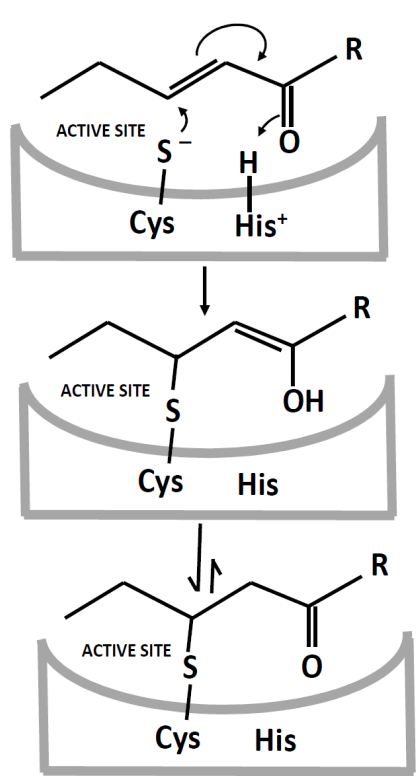

B 
Figure 3. Schemes for covalent binding of Cys in the active site to the ligands (A) polyphenol, (modified and drawn after Mazzei et al., 2017) (B) $\alpha, \beta$ - unsaturated carbonyl (modified and redrawn after https://zedira.com/Mechanism-of-TG-inhibitors/Michael-acceptorpeptidomimetics)

\section{Molecular Dynamic Simulation}

Molecular dynamics simulation validates in silico the stability of the protein ligand complex.A cubic simulation box with aqueous medium was setup with $10 \AA$ around the complex molecule accompanied by other default parameters of periodic boundary conditions. The protein is solvated by the transferable intermolecular potential 3 points (TIP3P) water model (density: $0.997 \mathrm{~g} \mathrm{~L}^{-1}$ ) inside the simulation cell. Salt $\mathrm{NaCl}$ (counter ions; $0.9 \%$ ) was added to neutralize the charges in the system. The system was energy minimized applying steepest gradient approach (100 cycles) using AMBER14. Constant pressure (1 bar), temperature $(298 \mathrm{~K})$ and $\mathrm{pH}=7.4$ were maintained during dynamic simulation (Berendsen $e t$ al., 1984). Particle Mesh Ewald (PME) method was implemented for estimation of longrange Coulomb electrostatics (Ewald, 1921; Darden et al., 1999). YASARA suite was used for molecular dynamic simulation for $20 \mathrm{~ns}$ (production period) with frame capture at every 250 ps step to analyze the trajectory by various evaluation parameters (Krieger and Vriend, 2014).

\section{Ligand Efficiency}

Ligand Efficiency (LE) is a parameter, which is useful for comparison of molecules according to their average binding energies per atom (Hopkins et al, 2014)

$$
\mathrm{LE}=(1.37 / \mathrm{HA}) * \mathrm{pIC}_{50} \text { OR LE }=(1.37 / \mathrm{HA}) * \mathrm{pKd}
$$

where, HA isthe number of non-hydrogen atom also called as heavy atom, $\mathrm{pIC}_{50}$ is the negative logarithm to the base 10 of the half-maximal inhibitory concentration, $\mathrm{pKd}$ is the negative logarithm to the base 10 of dissociation constant.

\section{Toxicity}

Toxicities of the phytochemicals were predicted using freely available ProTox-II virtual lab (http://tox.charite.de/protox_II) (Banerjee et al., 2018). A number of models of toxicity predictions are included in this method, like oral toxicity, hepatotoxicity, mutagenicity, carcinogenicity, cytotoxicity, immune-toxicity along with the metabolic pathways which are inhibited by the molecule (Banerjee et al., 2018). The toxicity is defined in terms of LD50 value ( $\mathrm{mg} / \mathrm{kg}$ body weight). The LD50 is the dose, which when administered to test subjects $50 \%$ of them die. The LD50 values are classified into six classes as follows:
a. Class 1: LD50 $\leq 5$ : fatal upon oral administration
b. Class 2: $5<\mathrm{LD} 50 \leq 50$ : fatal upon oral administration
c. Class 3: $50<$ LD50 $\leq 300$ : toxic upon oral administration
d. Class 4: $300<$ LD50 $\leq 2000$ : harmful upon oral administration
e. Class 5: $2000<$ LD50 $\leq 5000$ : may be harmful upon oral administration
f. Class 6: LD50 > 5000) : non-toxic upon oral administration

\section{Drug-Likeness}


MolSoft online server (http://www.molsoft.com/mprop) was used to compute Drug-likeness score from different molecular properties, i.e. molecular weight, number of hydrogen bond donors (HBD), number of hydrogen bond acceptors (HBA), polar surface area (PSA), MolLogP, MolLogS, and number of stereo centers. The score lies between -6.0 to 6.0. The curves for abundance of drug-like molecules show a peak at score 1.0.

\section{Structure Visualization and Data Table}

Molecular structures are visualized and Data tables are obtained using Biovia Discovery Studio Visualizer 16.1.0 tools. DS Visualizer is available from (https://www.3dsbiovia.com/products/collaborative-science/biovia-discovery-studio/ visualization-download.php)

\section{RESULTS}

\section{Non-covalent and Covalent Docking}

The results of screening the phytochemical against $\mathrm{M}^{\mathrm{pro}}$ active site is depicted in Table 1.

Table 1. Docking energy (BE), ligand efficiency (LE), pKd and covalent docking energy (CovBE) of phytochemical ligands obtained by docking in to the active site of $\mathrm{M}^{\text {pro }}$ using AutoDock Vina.

\begin{tabular}{lrrrr}
\hline \multicolumn{1}{c}{ Ligands } & $\begin{array}{r}\text { LE } \\
{[\mathrm{kcal} / \mathrm{mol}]}\end{array}$ & $\begin{array}{c}\text { BE } \\
{[\mathrm{kcal} / \mathrm{mol}]}\end{array}$ & pKd & $\begin{array}{c}\text { CovBE } \\
\text { [kcal/mol] }\end{array}$ \\
\hline 2,3-dihydroxybenzoicacid_CID_19 & 0.4739 & -5.213 & 3.821 & \\
4-hydroxybenzoicacid_CID_135 & 0.468 & -4.680 & 3.430 & \\
Aesculin_CID_5281417 & 0.2905 & -6.971 & 5.110 & \\
Apigenin_CID_5280443 & 0.3476 & -6.951 & 5.095 & \\
Apigenin-7-O- & & & & \\
glucuronide_CID_5319484 & 0.2777 & -8.888 & 6.515 & -23.66 \\
CaffeicAcid_CID_689043 & 0.4492 & -5.839 & 4.280 & -17.27 \\
ChlorogenicAcid_CID_1794427 & 0.3385 & -8.463 & 6.203 & -26.41 \\
Cynaroside_CID_5280637 & 0.2783 & -8.905 & 6.527 & \\
Esculetin_CID_5281416 & 0.428 & -5.564 & 4.078 & \\
Ethylgallate_CID_13250 & 0.3649 & -5.109 & 3.745 & \\
GallicacidCID_370 & 0.4423 & -5.307 & 3.890 & -17.03 \\
isoorientin_CID_114776 & 0.2716 & -8.692 & 6.371 & -23.32 \\
Isovitexin_CID_162350 & 0.2361 & -7.320 & 5.366 & \\
Luteolin_CID_5280445 & 0.3734 & -7.842 & 5.748 & \\
Luteolin-7-O- & & & & \\
glucuronide_CID_13607752 & 0.2727 & -9.000 & 6.597 & -24.23 \\
Methylgallate_CID_7428 & 0.4123 & -5.360 & 3.929 & \\
Molludistin_CID_44258315 & 0.2542 & -7.627 & 5.910 & -20.35 \\
Orientin_CID_5281675 & 0.2571 & -8.228 & 6.031 & -24.60 \\
Stigmasterol_CID_5280794 & 0.2447 & -7.342 & 5.382 & \\
UrsolicAcid_CID_64945 & 0.2143 & -7.073 & 5.185 & \\
Vicenin 2_CID_442664 & 0.2011 & -8.448 & 6.192 & \\
Vitexin_CID_5280441 & 0.2685 & -8.323 & 6.101 & -21.18 \\
\hline
\end{tabular}


There are two types of possibilities of C-S (Cys145) covalent bonding in some of the compounds listed in Table 1: (1) catechol, resorcinol or gallol group or $\alpha, \beta$-unsaturated carbonyl moiety (caffeic acid, chlorogenic acid) as per the mechanisms depicted in Fig. 3. The covalent docking energies are presented in the Table 1.

Table 2. Toxicity and drug-likeness properties of the phytochemicals of Tulsi

\begin{tabular}{|c|c|c|c|c|c|c|c|c|}
\hline Phytochemicals & $\mathrm{LD}_{50}$ & HBA & HBD & Rings & $\begin{array}{c}\text { Rotable } \\
\text { bonds }\end{array}$ & Charge & PSA & $\begin{array}{c}\text { Drug- } \\
\text { Likeness } \\
\text { Score } \\
\end{array}$ \\
\hline $\begin{array}{l}\text { 2, 3-dihydroxy } \\
\text { benzoicacid_CID_19 }\end{array}$ & 1800 & 4 & 3 & 1 & 1 & 0 & 77.76 & 0.32 \\
\hline $\begin{array}{l}\text { 4-hydroxy } \\
\text { benzoicacid_CID_135 }\end{array}$ & 2200 & 3 & 2 & 1 & 1 & 0 & 57.53 & -0.37 \\
\hline Aesculin_CID_5281417 & 4000 & 9 & 5 & 3 & 3 & 0 & 149.82 & 0.02 \\
\hline Apigenin_CID_5280443 & 2500 & 5 & 3 & 3 & 1 & 0 & 90.90 & 0.39 \\
\hline $\begin{array}{l}\text { Apigenin-7- } \\
\text { glucuronide_CID_5319484 }\end{array}$ & 5000 & 11 & 6 & 4 & 4 & 0 & 187.12 & 0.67 \\
\hline CaffeicAcid_CID_689043 & 2980 & 4 & 3 & 1 & 2 & 0 & 77.76 & -0.35 \\
\hline ChlorogenicAcid_CID_1794427 & 5000 & 9 & 6 & 2 & 5 & 0 & 164.75 & 0.79 \\
\hline Cynaroside_CID_5280637 & 5000 & 11 & 7 & 4 & 4 & 0 & 190.28 & 0.60 \\
\hline Esculetin_CID_5281416 & 945 & 4 & 2 & 2 & 0 & 0 & 70.67 & -1.22 \\
\hline Ethylgallate_CID_13250 & 5810 & 5 & 3 & 1 & 3 & 0 & 86.99 & -0.39 \\
\hline GallicacidCID_370 & 2000 & 5 & 4 & 1 & 1 & 0 & 97.99 & -0.22 \\
\hline isoorientin_CID_114776 & 159 & 11 & 8 & 4 & 3 & 0 & 201.28 & 0.59 \\
\hline Isovitexin_CID_162350 & 159 & 10 & 7 & 4 & 3 & 0 & 181.05 & 0.59 \\
\hline Luteolin_CID_5280445 & 3919 & 6 & 4 & 3 & 1 & 0 & 111.13 & 0.29 \\
\hline $\begin{array}{l}\text { Luteolin-7-O- } \\
\text { glucuronide_CID_13607752 }\end{array}$ & 5000 & 12 & 7 & 4 & 4 & 0 & 207.35 & 0.71 \\
\hline Methylgallate_CID_7428 & 1700 & 5 & 3 & 1 & 2 & 0 & 86.99 & -0.65 \\
\hline Molludistin_CID_44258315 & 832 & 9 & 5 & 4 & 3 & 0 & 149.82 & 0.90 \\
\hline Orientin_CID_5281675 & 1213 & 11 & 8 & 4 & 3 & 0 & 201.28 & 0.59 \\
\hline Stigmasterol_CID_5280794 & 890 & 1 & 1 & 4 & 5 & 0 & 20.23 & 0.62 \\
\hline UrsolicAcid_CID_64945 & 2000 & 3 & 2 & 5 & 1 & 0 & 57.53 & 0.66 \\
\hline Vicenin 2_CID_442664 & 536 & 15 & 11 & 5 & 5 & 0 & 271.20 & 0.20 \\
\hline Vitexin_CID_5280441 & 1213 & 4 & 3 & 4 & 3 & 0 & 181.05 & 0.60 \\
\hline
\end{tabular}

Table 3. Binding energies, toxicity and drug-likeness properties of some potent inhibitors not present in Tulsi

\begin{tabular}{|c|c|c|c|c|c|c|}
\hline Ligand & LE & $\begin{array}{c}\text { BE } \\
{[\text { Kcal/mol] }}\end{array}$ & pKd & $\begin{array}{c}\text { CovBE } \\
{[\mathrm{kcal} / \mathrm{mol}]}\end{array}$ & LD50 & $\begin{array}{c}\text { Drug- } \\
\text { Likeness } \\
\text { Score }\end{array}$ \\
\hline ALD & 0.198 & -6.754 & 4.951 & -18.17 & 3000 & -1.42 \\
\hline EGCG_CID_65064 & 0.286 & -9.423 & 6.907 & -24.59 & 1000 & 0.39 \\
\hline
\end{tabular}


Some physico-chemical properties along with their drug-likeness and toxicity of compounds present in Tulsi are represented in Table 2. Drug likeness, toxicity and binding energy of twosynthetic inhibitors ALD (N-[(benzyloxy)carbonyl]-L-leucyl-N-[(2S)-1-hydroxy-4methylpentan-2-yl]-L-leucinamide, papain, PDB ID 1bp4), O6K ( $\mathrm{M}^{\mathrm{pro}}$ ) and a phytochemical EGCG with gallol and catechol moieties found in green tea is exhibited for comparison (Table 3).

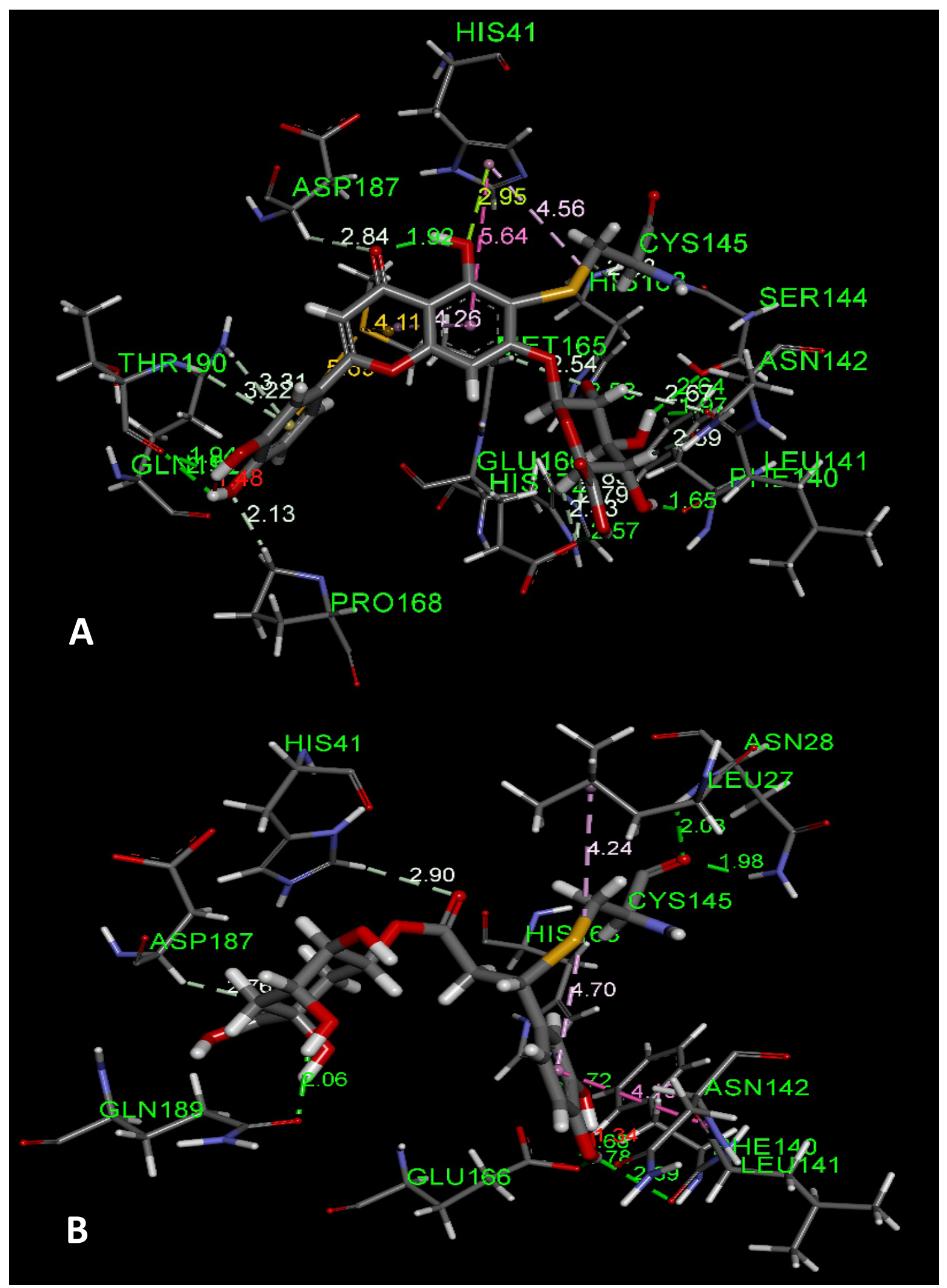




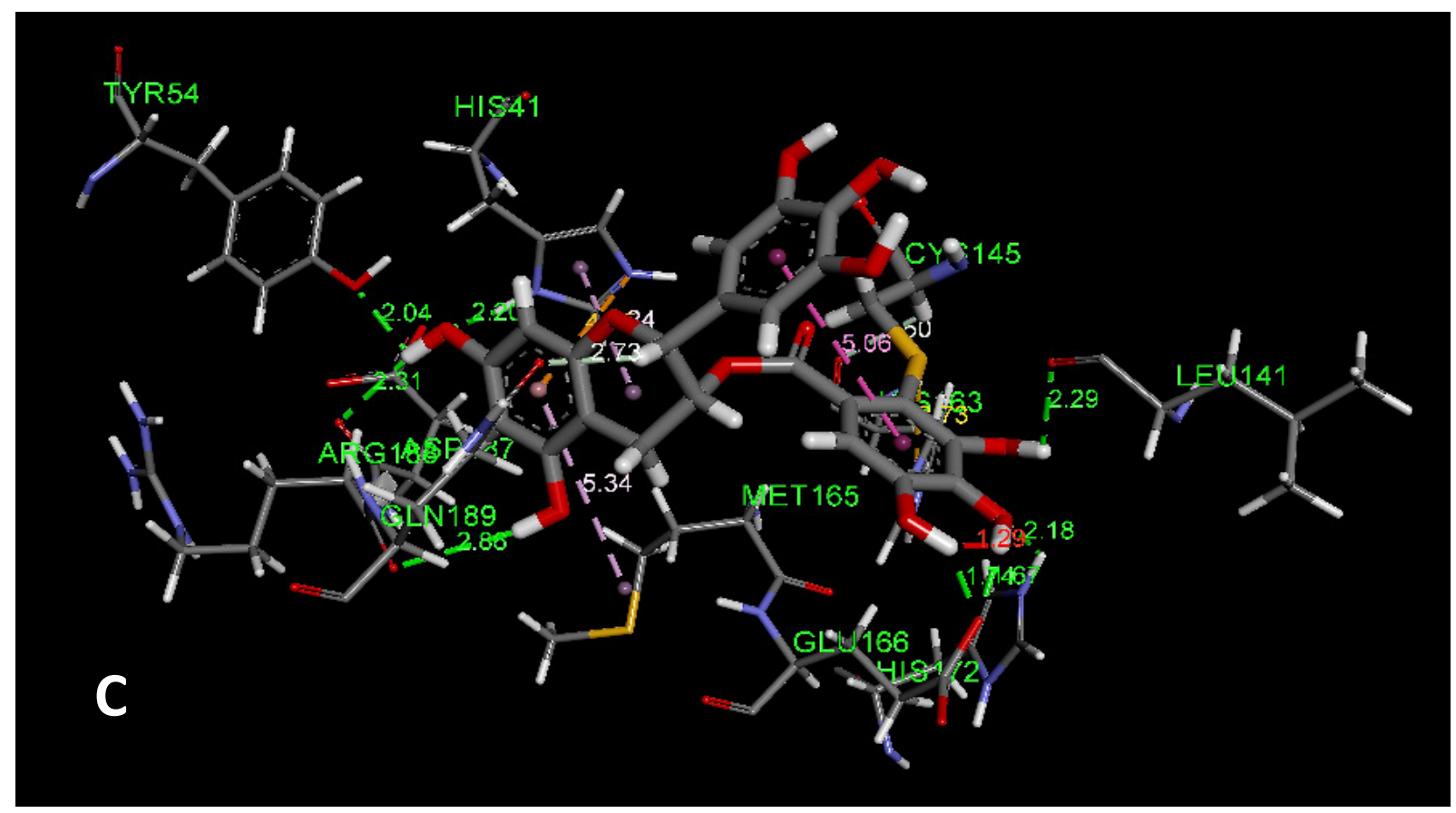

Interactions
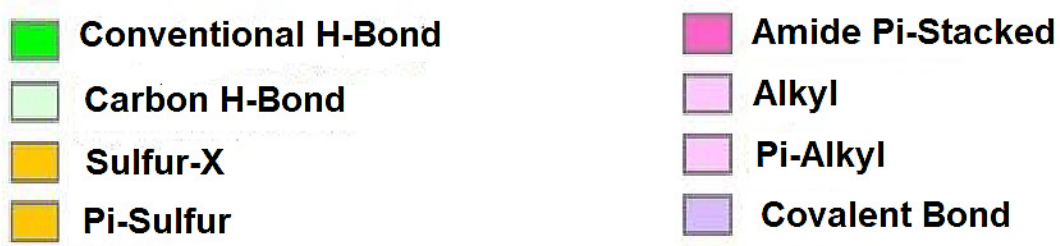

Figure 4. Interaction of ligands with main protease residues in the active site. A, Luteolin-7O-glucuronide; B, chlorogenic acid; C, EGCG.

Table 4. Details of the interactions of Ligand (LIG1) luteolin-7-O-glucuronide with the active site of the $\mathrm{M}^{\mathrm{pro}}$.

\begin{tabular}{lllllll}
\hline Category & \multicolumn{1}{c}{ Types } & \multicolumn{1}{c}{ From } & \multicolumn{1}{c}{ Chemistry } & \multicolumn{1}{c}{ To } & Chemistry & D [Å] \\
\hline HB & Conventional HB & A:LIG1:H & H-Donor & A:LEU141:O & H-Acceptor & 1.970 \\
HB & Conventional HB & A:LIG1:H & H-Donor & A:SER144:OG & H-Acceptor & 2.636 \\
HB & Conventional HB & A:LIG1:H & H-Donor & A:HIS163:NE2 & H-Acceptor & 2.581 \\
HB & Conventional HB & A:LIG1:H & H-Donor & A:PHE140:O & H-Acceptor & 1.650 \\
HB & Conventional HB & A:LIG1:H & H-Donor & A:GLU166:OE1 & H-Acceptor & 2.566 \\
HB & Conventional HB & A:LIG1:H & H-Donor & A:LIG1:O & H-Acceptor & 1.916 \\
HB & Conventional HB & A:LIG1:H & H-Donor & A:THR190:O & H-Acceptor & 1.940
\end{tabular}




\begin{tabular}{lllllll} 
HB & Conventional HB & A:LIG1:H & H-Donor & A:THR190:O & H-Acceptor & 2.152 \\
HB & Carbon HB & A:CYS145:HA & H-Donor & A:HIS163:O & H-Acceptor & 2.883 \\
HB & Carbon HB & A:MET165:HA & H-Donor & A:LIG1:O & H-Acceptor & 2.540 \\
HB & Carbon HB & A:PRO168:HD2 & H-Donor & A:LIG1:O & H-Acceptor & 2.126 \\
HB & Carbon HB & A:ASP187:HA & H-Donor & A:LIG1:O & H-Acceptor & 2.837 \\
HB & Carbon HB & A:LIG1:H & H-Donor & A:GLU166:OE1 & H-Acceptor & 2.791 \\
HB & Carbon HB & A:LIG1:H & H-Donor & A:HIS172:NE2 & H-Acceptor & 2.833 \\
HB & Carbon HB & A:LIG1:H & H-Donor & A:LEU141:O & H-Acceptor & 2.672 \\
HB & Carbon HB & A:LIG1:H & H-Donor & A:ASN142:OD1 & H-Acceptor & 2.593 \\
HB & Carbon HB & A:LIG1:H & H-Donor & A:GLU166:OE1 & H-Acceptor & 2.432 \\
HB & Pi-Donor HB & A:THR190:HN & H-Donor & A:LIG1 & Pi-Orbitals & 3.215 \\
HB & Pi-Donor HB & A:GLN192:HE22 & H-Donor & A:LIG1 & Pi-Orbitals & 3.308 \\
Other & Pi-Sulfur & A:MET165:SD & Sulfur & A:LIG1 & Pi-Orbitals & 4.114 \\
Other & Pi-Sulfur & A:MET165:SD & Sulfur & A:LIG1 & Pi-Orbitals & 5.685 \\
Other & Pi-Lone Pair & A:LIG1:O & Lone Pair & A:HIS41 & Pi-Orbitals & 2.951 \\
Hydrophobic & Pi-Pi T-shaped & A:HIS41 & Pi-Orbitals & A:LIG1 & Pi-Orbitals & 5.644 \\
Hydrophobic & Pi-Alkyl & A:HIS41 & Pi-Orbitals & A:CYS145 & Alkyl & 4.558 \\
Hydrophobic & Pi-Alkyl & A:LIG1 & Pi-Orbitals & A:MET165 & Alkyl & 4.263 \\
\hline HB, Hydrogen & bond D, Distance betWEen interacting atoms. & &
\end{tabular}

$\mathrm{HB}$, Hydrogen bond; D, Distance between interacting atoms.

Table 5. Details of the interactions of Ligand (LIG1) chlorogenic acid with the active site of the $\mathrm{M}^{\mathrm{pro}}$.

\begin{tabular}{lllllll}
\hline Category & Types & From & Chemistry & To & Chemistry & D [Å] \\
\hline HB & Conventional HB & A:ASN28:HN & H-Donor & A:CYS145:O & H-Acceptor & 2.029 \\
HB & Conventional HB & A:ASN28:HD22 & H-Donor & A:CYS145:O & H-Acceptor & 1.979 \\
HB & Conventional HB & A:HIS163:HE2 & H-Donor & d:LIG1:O2 & H-Acceptor & 1.719 \\
HB & Conventional HB & d:LIG1:HO2 & H-Donor & A:GLU166:OE1 & H-Acceptor & 1.675 \\
HB & Conventional HB & d:LIG1:HO3 & H-Donor & A:PHE140:O & H-Acceptor & 2.893 \\
HB & Conventional HB & d:LIG1:HO3 & H-Donor & A:GLU166:OE1 & H-Acceptor & 1.777 \\
HB & Conventional HB & d:LIG1:HO8 & H-Donor & A:GLN189:OE1 & H-Acceptor & 2.064 \\
HB & Carbon HB & A:HIS41:HE1 & H-Donor & d:LIG1:O1 & H-Acceptor & 2.899 \\
HB & Carbon HB & A:ASP187:HA & H-Donor & d:LIG1:O5 & H-Acceptor & 2.761 \\
& Amide-Pi & A:LEU141:C,O; & & & & \\
Hydrophobic & Stacked & ASN142:N & Amide & d:LIG1 & Pi-Orbitals & 4.103 \\
Hydrophobic & Alkyl & A:CYS145 & Alkyl & A:LEU27 & Alkyl & 4.241 \\
Hydrophobic & Pi-Alkyl & d:LIG1 & Pi-Orbitals & A:CYS145 & Alkyl & 4.696 \\
\hline
\end{tabular}

HB, Hydrogen bond; D, Distance between interacting atoms.

Table 6. Details of the interactions of Ligand (LIG1) EGCG with the active site of the $\mathrm{M}^{\text {pro }}$.

\begin{tabular}{lllllll}
\hline Category & Types & From & Chemistry & To & Chemistry & D [Å] \\
\hline HB & Conventional HB & A:HIS41:HD1 & H-Donor & LIG1:O10 & H-Acceptor & 2.201 \\
HB & Conventional HB & A:HIS172:HE2 & H-Donor & LIG1:O4 & H-Acceptor & 2.185 \\
HB & Conventional HB & LIG1:H3 & H-Donor & A:GLU166:OE1 & H-Acceptor & 1.739 \\
HB & Conventional HB & LIG1:H4 & H-Donor & A:GLU166:OE1 & H-Acceptor & 1.674
\end{tabular}




\begin{tabular}{lllllll} 
HB & Conventional HB & LIG1:H5 & H-Donor & A:LEU141:O & H-Acceptor & 2.289 \\
HB & Conventional HB & LIG1:H9 & H-Donor & A:ARG188:O & H-Acceptor & 2.859 \\
HB & Conventional HB & LIG1:H10 & H-Donor & A:TYR54:OH & H-Acceptor & 2.041 \\
HB & Conventional HB & LIG1:H10 & H-Donor & A:ASP187:O & H-Acceptor & 2.307 \\
HB & Conventional HB & A:CYS145:HA & H-Donor & A:HIS163:O & H-Acceptor & 2.503 \\
HB & Conventional HB & LIG1:H1 & H-Donor & A:GLN189:OE1 & H-Acceptor & 2.732 \\
Electrostatic & Pi-Cation & A:HIS41:NE2 & Positive & LIG1 & Pi-Orbitals & 4.451 \\
Other & Pi-Sulfur & A:CYS145:SG & Sulfur & A:HIS163 & Pi-Orbitals & 3.731 \\
Hydrophobic & Pi-Pi T-shaped & LIG1 & Pi-Orbitals & LIG1 & Pi-Orbitals & 5.056 \\
Hydrophobic & Pi-Alkyl & A:HIS41 & Pi-Orbitals & LIG1 & Alkyl & 5.245 \\
Hydrophobic & Pi-Alkyl & LIG1 & Pi-Orbitals & A:MET165 & Alkyl & 5.342 \\
\hline
\end{tabular}

HB, Hydrogen bond; D, Distance between interacting atoms.

\section{The Leads}

Three phytochemicals, luteolin-7-O-glucuronide, chlorogenic acid, and EGCG are selected for further study as lead molecules considering BE, CovBE, LD50, and Drug-likeness score taken together. There interactions with the active site residues are presented in Fig. 4 and details in Table 4-6.

\section{Molecular Dynamic Simulations}

The trajectories of the RMSD of $\mathrm{C} \alpha$ of backbone of protein-ligand complexes for $20 \mathrm{~ns}$ are presented in Fig. 5. The values are below $2.0 \AA$.

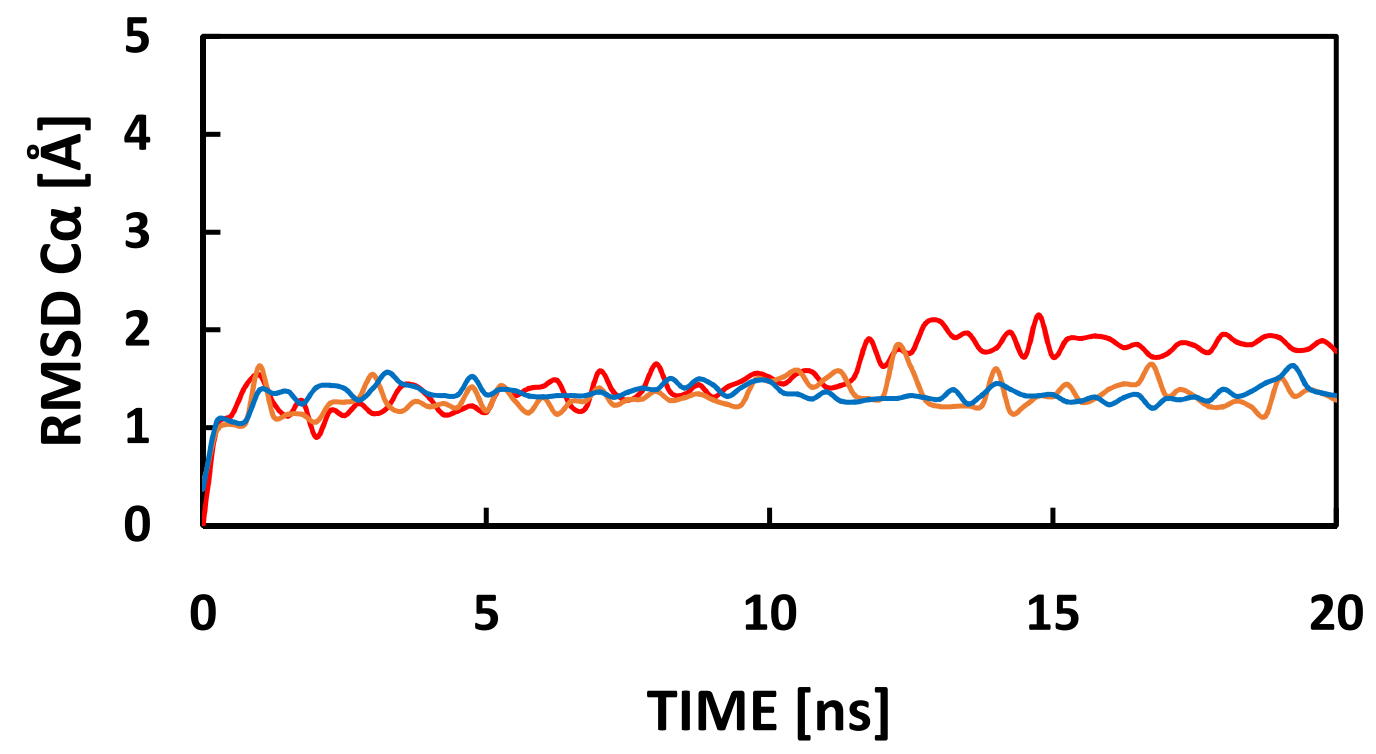

Figure 5. Trajectory of ligand-protein complex during molecular dynamic simulations. Luteolin-7-O-glucuronide (red), chlorogenic acid (brown), EGCG (blue). 


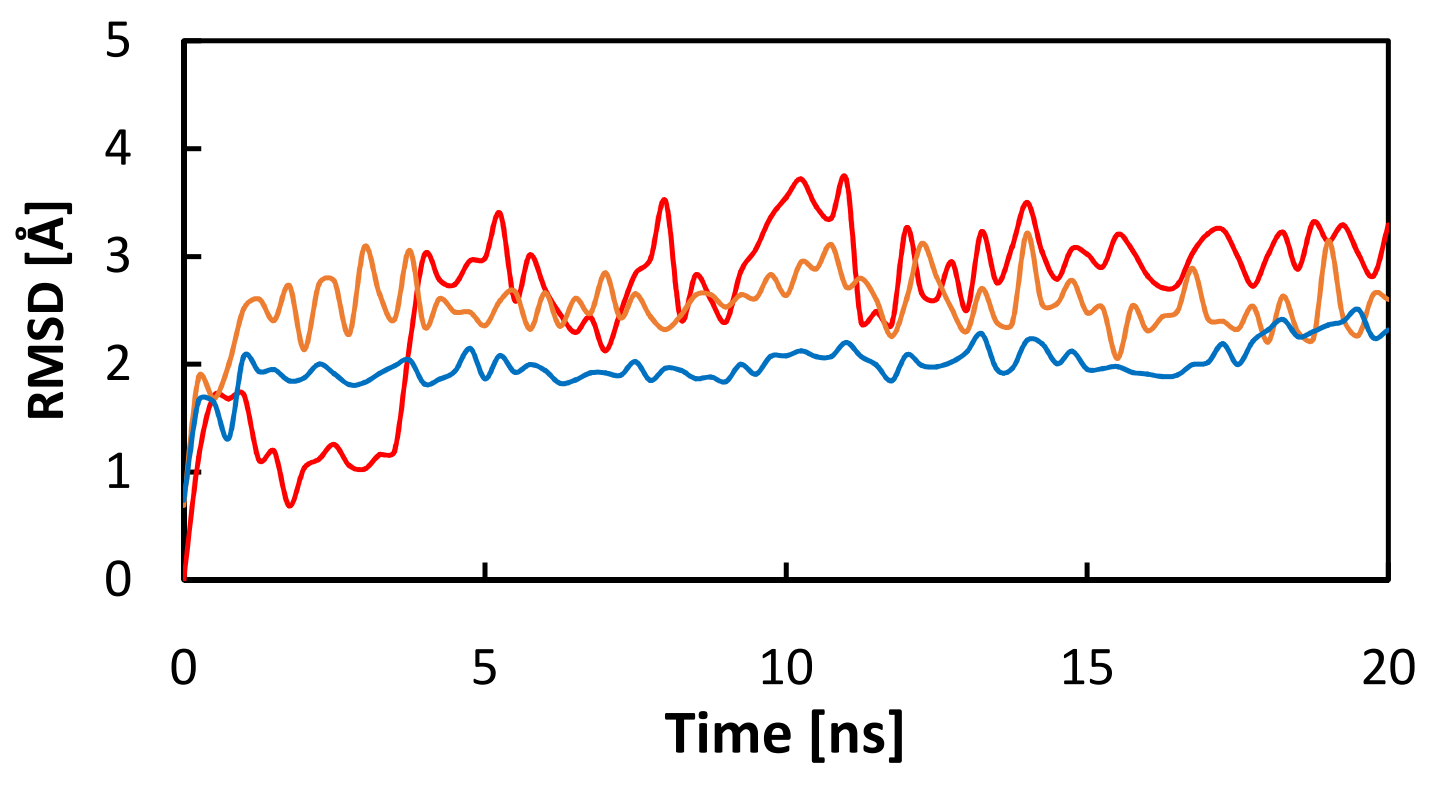

Figure 6. Ligand movement trajectory during molecular dynamic simulations. Luteolin-7-Oglucuronide (red), chlorogenic acid (brown), EGCG (blue).

The trajectories of the RMSD of ligand movement during simulations are depicted in Fig. 6. The values are below $2.0 \AA$ for EGCG and around $3.0 \AA$ for luteolin-7-O-glucuronide, chlorogenic acid.

\section{DISCUSSION}

\section{Non-covalent Docking}

There are several phytochemicals present in Tulsi, which have docking BE $>-8.0 \mathrm{kcal} / \mathrm{mol}$ and $\mathrm{pKd}>6.0 \mathrm{M}$. These phytochemicals are expected to bind tightly with stability to the active site of $\mathrm{M}^{\text {pro }}$ inhibiting its function to process viral proteins. All of them are flavonoids containing catechol or resorcinol moieties, except chlorogenic acid which has $\alpha, \beta$ unsaturated carbonyl moiety (Table 1). They all have potential to form C-S (Cys145) covalent bond leading to irreversible covalent inhibitors.

\section{Covalent Inhibitors}


Covalent inhibitors have been approved as drugs by FDA since a decadereversing the trend of disallowing it with a fear of toxic effects (Awoonor-Williams et al., 2017; Sotriffer, 2018; Ghosh et al., 2019). Several advantages of the covalent drugs have encouraged its designing in the present time. The covalent binding can improve the selectivity of the drug for a target increase in binding affinities as a result of a strongcovalent bond.It may lead to long half-life period of protein ligand interaction and prolong dosing time. Shallow binding sites may be targeted through covalent binding (Tuley and Fast, 2018).The disadvantages are modification of non-target proteins, nucleic acids, or small molecules through random reaction, inability to sustained response if the target enzyme has rapid turnover rate (Tuley and Fast, 2018). Above all the entire exercise would be futile if the ligand binding residue of the target is specifically mutated by the organism (Ghosh et al., 2019).

In the present study the target $\mathrm{M}^{\text {pro }}$ is a Cys-protease. $\mathrm{SG}$ of the active residue Cys145 is targeted for the covalent drug binding. If the viral system mutates Cys 145 the protease activity itself will be impaired and suicidal. Hence the chance of development of resistance may be eliminated. Around $-24.0 \mathrm{kcal} / \mathrm{mol}$ of $\mathrm{BE}$ of covalent docking of phytochemicalsreflects a high potentiality of stability and specificity.

\section{Comparison with Reported Cys protease Inhibitors}

The crystal structure of $\mathrm{M}^{\text {pro }}$ (PDB ID 6y2f) has been reported with a covalently bound synthetic inhibitor O6K (Zhang et al., 2020). It is an $\alpha$-ketoamide inhibitor with a carbonyl warhead forming C-S covalent bond with Cys145 (Fig. 2). The non-covalent and covalent docking energies by the present method were estimated to be $-7.118 \mathrm{kcal} / \mathrm{mol}$ and-27.32 $\mathrm{kcal} / \mathrm{mol}$ respectively (Table 4). The compound is experimentally estimated to has $\mathrm{IC}_{50}=$ $0.67 \pm 0.18 \mu \mathrm{M}$ against pure $\mathrm{M}^{\text {pro }}$ from SARS-CoV-2 (Zhang et al., 2020). The binding energies are comparable with the lead phytochemicals while toxicity and drug-likeness criteria are better than that of O6K. ALD (PDB ID 1bp4), another $\alpha$-ketoamide, which inhibits papain (a Cys-protease) has even poorer criteria (Table 4).

\section{EGCG}

EGCG though not found in Tulsi, it is a suitable one to be one of the lead compounds when compared to other phytochemicals in Tulsi. EGCG is found predominantly in green tea besides other plants.

\section{CONCLUSION}

In silico analysis of phytochemicals mostly flavonoids and polyphenolic acids in Tulsi exhibit potentiality to be inhibitors of $\mathrm{M}^{\text {pro }}$. These phytochemicals are experimentally found to be effective anti-viral against some viruses (Weng et al, 2019; Jo et al., 2019). Chlorogenic acid and luteolin-7-O-glucuronide emerge as lead molecules. Chlorogenic acid is present predominantly in coffee beans. Flavonoids are known to inhibit SARA Cov 3CL (homologous to $\mathrm{M}^{\text {pro }}$ SARS Cov2) (Jo et al., 2019).

The present study is purely theoretical. The findings are explained in terms of previous experimental results. However, several steps lie ahead to confirm and validate the present result experimentally before a solid conclusion is reached. 


\section{REFERENCES}

Awoonor-Williams A, Walsh AG, Rowley CN (2017) Modeling covalent-modifier drugs. Biochim Biophys Acta Proteins Proteom 1865(11 Pt B): 1664-1675

Banerjee P, Eckert AO, Schrey AK, Preissner R (2018) ProTox-II: a webserver for the prediction of toxicity of chemicals. Nucleic Acids Res 46: W257-W263

Berendsen HJC, Postma JPM, van Gunsteren WF, DiNola A, Haak JR (1984) Molecular dynamics with coupling to an external bath. J Chem Phys 81: 3684-3690

Bhasin M (2012) Ocimum-taxonomy, medicinal potentialities and economic value of essential oil. J Biosph 1: 48-50

Bianco G, Forli S, Goodsell DS, Olson AJ (2016) Covalent docking using Autodock: twopoint attractor and flexible side chain methods. Prot Sci 25: 295-301

Darden T, Perera L, Li L, Pedersen L (1999). New tricks for modelers from the crystallography toolkit: The particle mesh Ewald algorithm and its use in nucleicacid simulations. Structure 7: R55-R60

Ewald P (1921) Die Berechnung optischer und elektrostatischergitterpotentiale. Annals Phys 64: $253-287$

Ghosh A, Samanta I, Mondal A, Liu WR (2019) Covalent inhibition in drug discovery. Chem Med Chem 14: 889-906

Hopkins AL, Keseru GM, Leeson PD, Rees DC, Reynolds CH (2014) The role of ligand efficiency matrics in drug discovery. Nat Rev Drug Discov 13: 105-121

Jackson PA, John C. Widen JC, Harki DA, Brummond KM (2017) J Med Chem 60: 839-885

Jo S, Kim S, Shin HD, Kim MS (2019) Inhibition of SARS-CoV 3CL protease by flavonoids. J Enzyme Inhibit Med Chem 35: 145-151

Krieger E, Vriend G (2014) YASARA view - molecular graphics for all devices - from smartphones to workstations. Bioinformatics 30: 2981-2982

Mazzei L, Cianci M, Musiani F, Lente G, Palombo M, Ciurli S (2017) Inactivation of urease by catechol: Kinetics and structure. J Inorg Biochem 166: 182-189

Mondal S, Mirdha BR, Mahapatra SC (2009) The science behind sacredness of Tulsi(Ocimum sanctum Linn.) Indian J Physiol Pharmaco 153: 291-306

Morris GM, Goodsell DS, Halliday RS, Huey R, Hart WE, Belew RK, Olson AJ (1998) Automated docking using a lamarckian genetic algorithm and empirical binding free energy function. JComputChem19:1639-1662 
Sotriffer C (2018) Docking of covalent ligands: challenges and approaches. Mol Inf 37: 1800062

Trott O, Olson AJ (2010) AutoDock Vina: Improving the speed and accuracy of docking with a new scoring function, efficient optimization, and multithreading. J Comput Chem 31: $455-461$

Tuely A, Fast W (2018) The taxonomy of covalent inhibitors. Biochemistry 57: 3326-3337

Weng JR, Lin CS, Lai HC, Lin YP, Wang CY, Tsai YC, Wu KC, Huang SH, Lin CW (2019) Antiviral activity of Sambucus Formosana Nakai ethanol extract and related phenolic acid constituents against human coronavirus NL63. Virus Res 273: 197767

Zaharan EM, Abdelmohsen UR, Khalil HE, Desoukey SY, Fouad MA, Kamel MS (2020) Diversity, phytochemical and medicinal potential of the genus Ocimum L. (Lamiaceae) Phytochem Rev doi.org/10.1007/s11101-020-09690-9

Zhang L, Lin D, Sun X, Curth U, Drosten C, Sauerhering L, Becker S, Rox K, Hilgenfeld R (2020) Crystal structure of SARS-CoV-2 main protease provides a basis for design of improved $\alpha$-ketoamide inhibitors. Science 368: 409-412 